\title{
TRANSIENT UNILATERAL PNEUMOPAROTID FOLLOWING UPPER ENDOSCOPY
}

\author{
Pillay $Y^{1}$, Goh $K L^{2}$ \\ 1 Victoria Hospital, Prince Albert Parkland Health Region, Prince Albert, Saskatchewan, Canada \\ 2 Department of Medicine, University of Malaya, Kuala Lumpur, Malaysia \\ Correspondence: \\ Yagan Pillay \\ $33106^{\text {th }}$ Avenue West, Prince Albert, SK \\ S6V8C3, Canada \\ Email: yagan2pillay@yahoo.ca
}

\begin{abstract}
Salivary gland swelling is a rare complication of upper endoscopy with less than twelve cases reported in the literature. The swelling is usually transient in nature, with complete resolution in a few hours. While all the major paired salivary glands have been implicated, the exact aetiology remains obscure. In this case report, a sixty one year old female presents with unilateral swelling of the right parotid gland immediately following an upper endoscopy. There was complete resolution of the pneumoparotid with no neurological sequelae.
\end{abstract}

Keywords: Endoscopic complications, pneumoparotid, salivary gland, transient salivary gland swelling, sialadenopathy

\section{Introduction}

A 61 year old Malay woman was referred for an upper endoscopy to our gastrointestinal unit. She complained of epigastric pain with relation to food. Symptomatic medical treatment did not alleviate her symptoms. Her medical history included Diabetes and Hypertension. She also suffered from Systemic Lupus Erythematosus (SLE) over the past thirty years but this was well controlled. Her premedication for the upper endoscopy consisted of Midazolam $2.5 \mathrm{mg}$ intravenously and Xylocaine spray to the mouth and oropharynx. The gastroscope was then performed and findings included multiple duodenal ulcers in the first part of the duodenum. There was no stigmata of bleeding. The rest of the endoscopy was normal. Post-operatively in the observation ward the patient complained of unilateral swelling to the right side of the face, immediately after the procedure.

Clinical examination revealed a swelling over the right parotid gland. The swelling was soft and mobile with no bruit or palpable thrill. There was no dysphagia or dysphonia. There was no bleeding from the mouth or any surgical crepitus around the neck. No obvious facial nerve injury was noted on either side. The patient remained clinically stable and her oxygen saturation was $95 \%$ on room air. Her upright chest roentgenogram was normal. The patient was kept under observation for three hours and remained stable throughout. The swelling subsided spontaneously with complete resolution. The patient was then sent home and put on eradication therapy for her duodenal ulcers. Follow-up a week later revealed no further swelling and the patient has remained asymptomatic.

\section{Discussion}

The term pneumoparotid was initially described by Hyrtl in 1865 , in musicians who were learning to play wind instruments $(1,2)$. Other terms for this condition include pneumatocele glandulae parotis, wind parotitis, surgical mumps, anesthesia mumps, and pneumosialadenitis (3). The anatomy of Stensen's duct usually prevents a retrograde influx of air. The normal intraoral pressure is $20 \mathrm{mmHg}$ which increases to $150 \mathrm{mmHg}$ with forceful exhalation of air within a closed mouth. The redundant mucosal folds that surround the slit-shaped orifice, and smaller diameter of the duct orifice prevent large increases in intraoral pressure $(1,2)$. Transient parotid swelling has been documented as a rare complication of upper endoscopy (4).There is thought to be an association with retching, though there have been cases without any retching recorded. The two types of submandibular swelling is attributed to air distention of blind branchial cleft remnants or salivary gland swelling e.g. the parotid gland (4). The hypothesized aetiology for the salivary gland swelling is the ductal compression between the mylohyoid and hyoglossus muscles (5). This is due to pressure from above during increased salivary flow as a result of oral stimulation during the endoscopy. 
This transient sialadenopathy has also been reported during the induction of anaesthesia with endotracheal intubation. Parasympathetic stimulation of the salivary glands is thought to cause vasodilatation and hyperemia. All the reported cases in the literature indicate that the salivary gland swelling is transient, painless and requires no treatment after removal of the endoscope (6). It is incumbent upon endoscopists to be aware of this rare complication so as to reassure the patient of its transient nature and lack of any real morbidity.

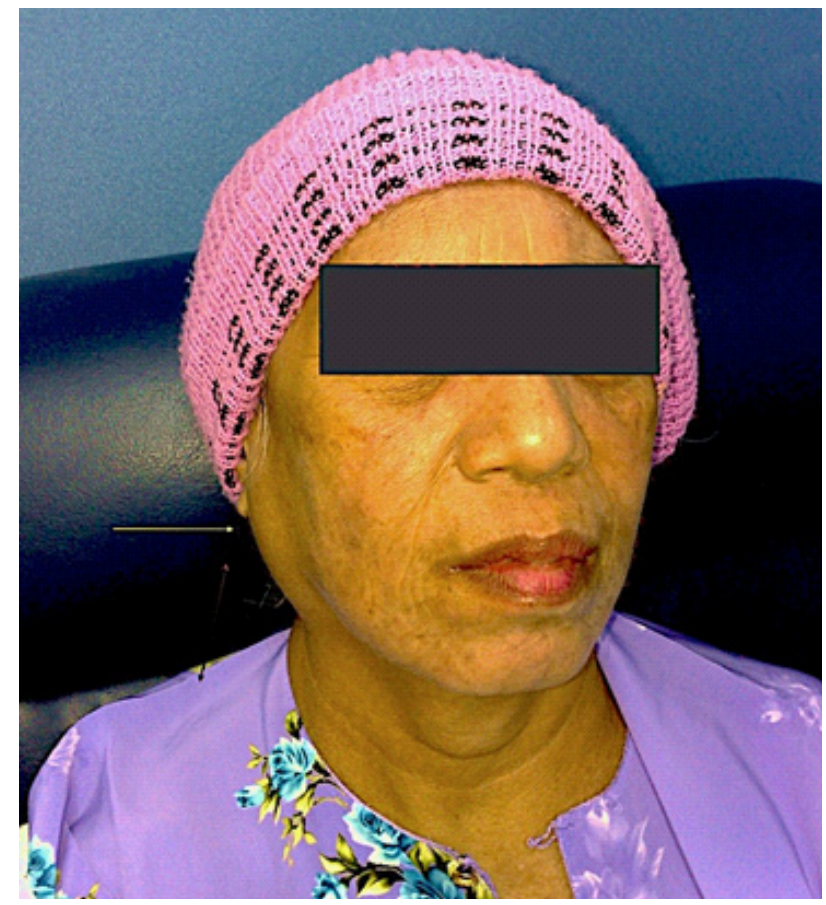

Figure 1: Right parotid swelling (yellow arrow)

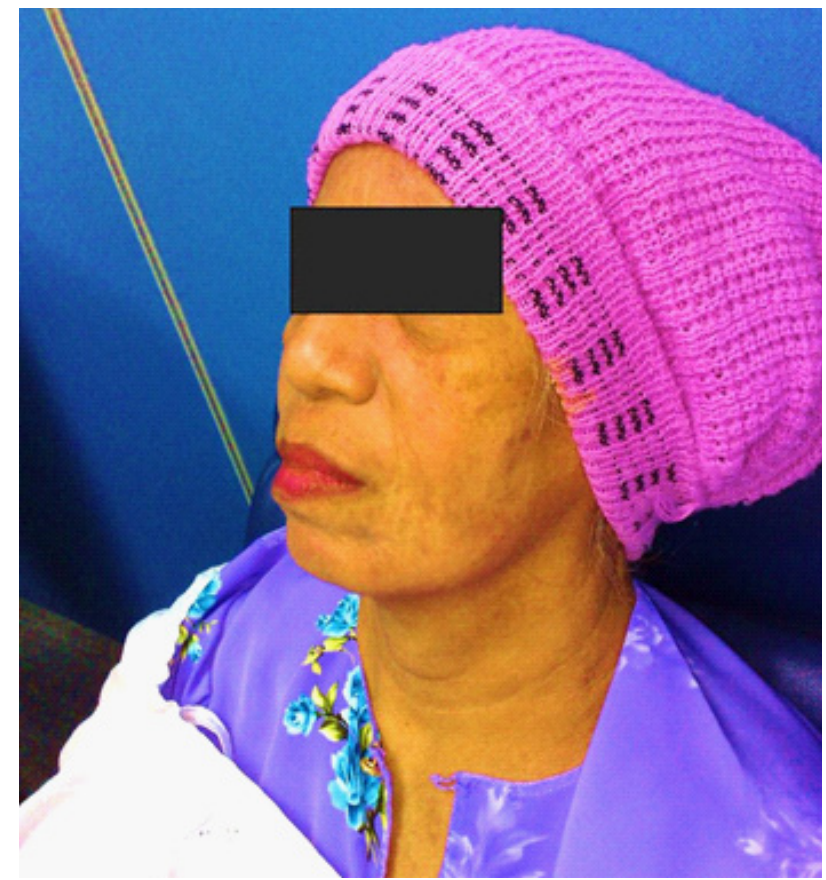

Figure 2: Normal left parotid gland

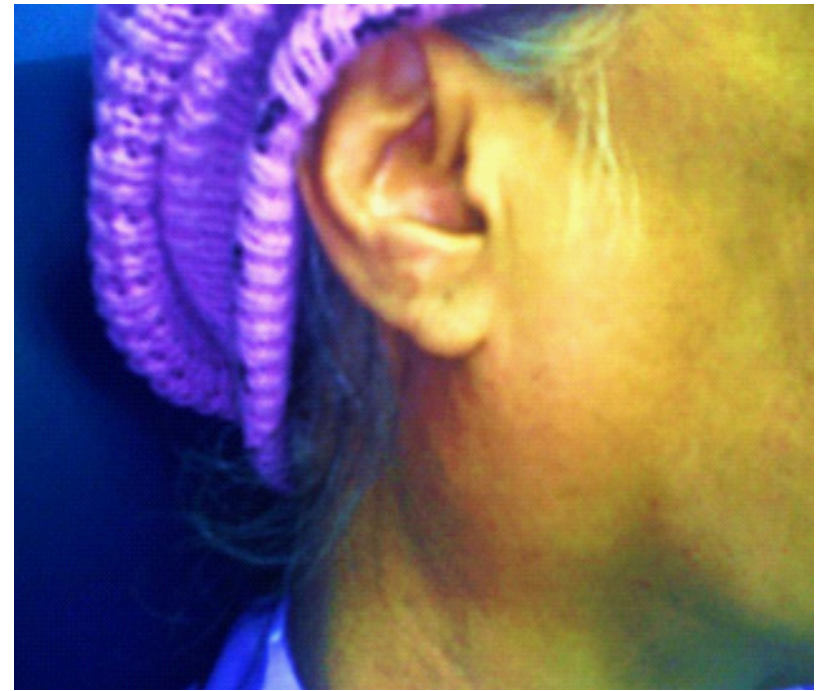

Figure 3: Right pneumoparotid lateral view

\section{Acknowledgement}

I would like to thank Prof. Dato' Dr. Goh Khean Lee for all his assistance during my tenure at University of Malaya Medical Centre in the Department of Medicine.

\section{References}

1. Markowitz-Spence L, Brodsky L, Siedell G, Stanievich JF. Self-induced pnemoparotitis in an adolescent: Report of a case and review of the literature. Int J Pediatr Otorhinolaryngol 1987; 14:113-121.

2. Greisen O. Pneumatocele glandulae parotis. J Laryngol Otol 1968; 82:477-80.

3. Han S, Isaacson G. Recurrent pneumoparotid: cause and treatment. Otolaryng Head Neck. 2004; 131(5):758-761.

4. Marvin J. Gordon. Transient submandibular swelling following esophagogastroduodenoscopy. Digest Dis Sci. 1976; 21(6):507-508.

5. Slaughter RL. Parotid gland swelling during peroral endoscopy. Gastrointest Endosc 1975; 22(1):38-39.

6. Lee $\mathrm{CY}$, Jang $\mathrm{S}$, Park JS, et al. Two Cases of Unilateral Transient Sialoadenopathy after Gastroscopy. Korean J Gastrointest Endosc. 1999; 19(6):935-938. 